\title{
DEMOCRACIA NO TERRITÓRIO DIGITAL ${ }^{1}$
}

\section{Ciberespaço é o novo território das trocas comunicacionais, livres de fronteiras e barreiras ideológicas}

O termo ciberespaço apareceu pela primeira vez no livro Neuromancer, de William Gibson, de 1984. Por vezes empregado como sinônimo de imagens de ambientes criados em computadores - principalmente em livros e congressos de arquitetura -, outras como sinônimo da Internet. Nas disciplinas de Comunicação, o ciberespaço é a trama informacional construída pelo entrelaçamento de meios de telecomunicação e informática, tanto digitais quanto analógicos, em escala global ou regional. Telefones, celulares, rádio e televisão, infra-estrutura de cabos de cobre ou fibras ópticas, ondas de rádio ou satélite, organizados em redes locais (Intranets, como, por exemplo, a ligação em rede entre os computadores das unidades da Universidade de São Paulo) ou globais, tendo seus terminais de comunicação ou suas informações gerenciadas por computadores, formam o ciberespaço.

Neste trabalho buscarei discutir ações que vêm sendo realizadas no ciberespaço que procuram criar estruturas democráticas - em esferas artísticas e políticas - e que, após a consolidação informacional no território digital, dinamizam transformações culturais no território geopolítico. Para isso, gostaria antes de discutir três pontos que nortearão o trabalho. A princípio, bus- carei colocar algumas noções de espaço e lugar no ciberespaço e a caracterização dos territórios digitais, com independência das proximidades geográficas. No item Internet, comentarei a origem, desenvolvimento e características da rede global de computadores que são essenciais para seu sucesso e para o desenvolvimento de projetos no $\mathrm{ci}$ berespaço. No item Descentralização e controle e nos demais, comentarei um dos princípios fundamentais da Internet, sua estrutura descentralizada, algumas tentativas de controle informacional por parte de governos nacionais, e essa impossibilidade de controle como força propulsora de ações nos territórios digitais ${ }^{2}$.

Um fator importante para se pensar o ciberespaço é a relação entre lugar e identidade. Numa perspectiva moderna, uma pessoa existe num determinado lugar em determinado tempo. Minha personalidade é tal por estar aqui neste congresso de comunicação, falando sobre determinado assunto, em São Paulo, no outono de 1998; diversamente será quando estiver à noite num restau-

\section{O AUTOR}

\section{Fábio Duarte}

Arquiteto, Mestre em Multimeios pela Unicamp - São Paulo.E-mail: fduarte@widesoft.com.br

1. Trabalho apresentado no Congresso Internacional sobre Comunicação e Educação, realizado em São Paulo, Brasil, em maio de 1998, coordenado pelo NCE - Núcleo de Comunicação e Educação do CCA-ECA-USP e pelo WCME - World Council for Media Education.

2. DUARTE, F. Global e local no mundo contemporâneo. São Paulo: Moderna, 1998. 
rante, com outras pessoas, outros interesses. Todavia, podemos estar em mais de um lugar ao mesmo tempo. Estou num congresso de comunicação e também em São Paulo e também num país que fala português etc. Quando tomo uma posição num espaço, determino um lugar; assim, um mesmo espaço assume características diversas, potencializa lugares segundo determinados interesses envolvidos. Isso não é, como vemos, exclusivo do ciberespaço, mas é importante para entendermos sua natureza.

O ciberespaço é formado por uma estrutura de meios de comunicação e de fluxos de informações, mas ele potencializa a constituição de ciberlugares, que têm como uma de suas características principais $a$ independência de posições geográficas.

Um exemplo marcante de ciberlugares é a formação de comunidades virtuais, pessoas que se conectam, formam grupos de discussão, trocam informações, enfim, aproximam-se por afinidades que não ligadas a suas localizações geográficas. Vivem, comunicam-se, trocam experiências em territórios digitais. Território que, tomando a definição da geografia, é uma porção do espaço com limites e, principalmente, com um gerenciamento desse espaço. No caso das comunidades do ciberespaço, esse território é construído através de afinidades distintas das que formam os territórios com dependência geográfica e/ou geopolítica. Os $\mathrm{ci}$ berlugares são construídos como pontes entre fatores, por vezes, extremamente localizados e o fluxo informacional global, integrando potencialidades locais, dispersas em um território com características similares. Considero esse ponto um dos mais importantes para entendermos a dinâmica da sociedade informacional que se forma no $\mathrm{ci}$ berespaço, no qual apoiarei meus exemplos.

\section{INTERNET}

A origem da Internet está ligada a uma estratégia de defesa norte-americana durante o período da Guerra Fria. Em 1969, foi criada a Arpanet, rede militar de computadores, com arquitetura informacional descentralizada, permitindo que os dados pudessem ser enviados e codificados através de várias e diferentes rotas. $\mathrm{O}$ objetivo principal das pesquisas que vinham sendo desenvolvidas para a construção da rede era que fosse resistente a um ataque nuclear, permitindo que as decisões e ações não estivessem concentradas num mesmo lugar.

Com o abrandamento e fim da Guerra Fria, a rede alastrou-se a outros setores dentro e fora do país, no princípio conectando universidades, bibliotecas e centros de pesquisa. Esta expansão tomou força na segunda metade dos anos 80 , sobretudo pelo desenvolvimento dos computadores pessoais, permitindo um uso civil da rede a baixo custo. No início dos anos 90 , o crescimento foi ainda maior com o interesse das empresas comerciais e sistemas financeiros no uso das redes informacionais, com serviços telefônicos privados cada vez mais baratos mesmo que as comunicações backbones (estrutura básica necessária ao funcionamento de uma rede de serviços; um tipo de tronco principal da rede com alta velocidade, operando com as maiores distâncias e maior tráfego) de alta velocidade continuem sendo públicas.

Mesmo estando hoje desvinculada de seu projeto original, uma de suas características fundamentais permanece: a descentralização. A Internet não é hierárquica, sua estrutura comunicacional é coordenativa. Além de descentralizada, não há necessidade de identificação geográfica dos agentes de informações - que são, concomitantemente, emissores e receptores -, e a mani- 
pulação de informações e ações pode ser feita remotamente. Com sua abrangência global, a Internet é parte integrante, e das mais dinâmicas, do ciberespaço, e vem se mostrando campo de atuação de forças locais que não conseguiam se exprimir através dos meios de comunicação anteriores, seja por custos em adquirir tecnologia, seja pela vigilância das forças políticas.

\section{DESCENTRALIZAÇÃO E CONTROLE}

Preocupados com o teor do material divulgado e discutido na Internet, diversos governos vêm buscando colocar limites ao conteúdo das informações disponíveis. No início de 1996, por exemplo, o Congresso norte-americano discutiu o Ato de Decência nas Comunicações, tentando eliminar material considerado "indecente" na Internet. Em votação, foi derrotado.

Perante a estrutura descentralizada, abrangência global sem fronteiras geopolíticas e fluxos codificados de informação, o controle na Internet é não só tecnologicamente impossível como também, por essas mesmas características, politicamente inviável.

$\mathrm{O}$ primeiro problema que poderíamos colocar tem cunho jurídico. Como notamos, não há bordas nacionais no ciberespaço, e quando acessamos uma informação na rede ela pode estar arquivada em um computador em qualquer outro país. É mesmo comum, estando em São Paulo, pesquisando qualquer tema num site francês, por exemplo, interessarmo-nos por determinado tópico e, ao clicá-lo, recebermos tal informação de um outro site, no Líbano. Essas migrações informacionais não passam por uma alfândega digital. Assim, onde controlar as informações? No serviço de comunicações do país onde o usuário está acessando-as ou onde elas estão armazenadas? Ambas as si- tuações são extremamente frágeis. O usuário pode agir remotamente no ciberespaço, através de uma ligação feita de um servidor estrangeiro, com a mesma facilidade que teria se estivesse em outro servidor, na cidade em que se encontra; e as informações podem estar armazenadas em diversos computadores em diferentes países, sendo que, quando buscamos acessá-las, o computador tenta encontrá-las da maneira mais eficiente. Desse modo, é muito difícil para um Estado controlar as informações recebidas por seus habitantes, restando-lhe apenas fechar todas as suas comportas, indistintamente, a qualquer informação.

A tentativa de uma legislação global sobre o teor das informações veiculadas na Internet esbarraria na soberania das nações, o que também a impossibilita. Além de fatores políticos internos, como nos Estados Unidos, onde se concentra o maior número de usuários da Internet, e a liberdade de expressão é preciosa.

Tecnologicamente, o modo mais comum de se controlar as informações que podem ser recebidas é a instalação de programa, como o NetNanny, que bloqueia o acesso aos sites que contiverem determinadas palavras. Mas isso é frágil. Ao bloquear a palavra sexo, por exemplo, ao mesmo tempo em que nações podem estar tentando impedir acesso a sites de pornografia, estarão também impedindo acesso a importantes discussões científicas, psicológicas ou sociais ligadas ao tema. Além disso, tais babás digitais conseguem decodificar palavras, mas não imagens. Se a palavra sexo não estiver na página acessada, ela aceita, sem conseguir verificar o teor da imagem. Um fator tecnologicamente importante das informações do ciberespaço (não apenas da Internet) é sua codificação digital, o que permite, na 
transmissão, que ela seja subdividida em diversos pacotes informacionais e que cada um deles tome rotas distintas, de acordo com o desempenho da rede naquele instante. Enquanto migram, normalmente os pacotes que seguem próximos são de mensagens vindas de lugares diferentes, com teores distintos - misturando som, imagem e texto -, que seguem inúmeras rotas, apenas com alguns dados que farão com que os pacotes se encontrem e reconstituam a mensagem original num determinado lugar. Isso impossibilita que as mensagens sejam rastreadas enquanto migram pelo ciberespaço.

$\mathrm{Na}$ tentativa de censurar as informações na Internet a seus habitantes, algumas nações proibiram seu uso ou bloquearam determinados sites. A revista The Economist denominou-os Estados NetNanny. A China, por exemplo, em 1996, bloqueou mais de $100 \mathrm{si}$ tes, incluindo a revista masculina Playboy, mas também diversos jornais e revistas, como a própria The Economist, além de diversos outros sites, principalmente os que continham informações sobre questões relativas ao Tibete e Taiwan, incluindo os mais importantes jornais e boletins de informação do mundo. Esses Estados, no entanto, sofrem o dilema de ao mesmo tempo querer integrarse à dinâmica econômica global e manter regimes repressivos ao livre acesso e à discussão das informações de caráter internacional.

Dois exemplos de tentativa de controle de informações do ciberespaço que nos mostram a superação dos padrões geopolíticos através da dinâmica do meio, contra a vontade dos governantes e o refluxo dessas informações sobre essas mesmas questões geopolíticas, são os casos recentes no México e na União Soviética. No México, em 1994, os zapatistas rebelados contra o governo do PRI (Partido Revolucionário Institucional, nome sintomaticamente contraditório), acantonados na região do Chiapas, conseguiram mobilizar os meios de comunicação e a opinião pública internacional para sua causa, divulgando informações na Internet, através de sites localizados em outros países. Na União Soviética, durante a tentativa de golpe de Estado em 1991, uma das medidas foi o corte das linhas telefônicas e a imobilização dos jornais. Porém, a estabilidade das ligações da Internet com a Finlândia, país forçosamente neutro durante a Guerra Fria, possibilitou que as informações sobre a situação soviética rapidamente adquirissem dimensão global, auxiliando a tomada de medidas contra o golpe.

\section{AÇÕES LOCAIS NO TERRITÓRIO GLOBAL}

Esses exemplos mostram como as características do ciberespaço, e notadamente da Internet, transformam não apenas a natureza dos meios de comunicação, mas também as concepções globais de espaço, lugar e identidade geopolítica. Com isso, gostaria de discutir duas experiências que souberam se aproveitar dessas características para desenvolver projetos políticos e artísticos no território digital: as discussões e ações do jornal francês Le Monde Diplomatique sobre a Internet na África, especialmente na Argélia, país sem condições tecnológicas mas também avesso à dinâmica cultural do ciberespaço; e a criação da V2-East, que vem congregando grupos artísticos de diversos países do antigo bloco comunista europeu, que por anos tiveram dificuldades ou impossibilidade de trocar informações com outros países e que encontraram no ciberespaço um território de manifestação.

A V2-Organisatie é um centro de arte e tecnologias baseado em Roterdã, Holanda. No início dos anos 90 começou a mostrar interesse crescente pelas experiências artís- 
ticas, envolvendo países do Leste Europeu. Contudo, as restrições econômicas e tecnológicas não permitiam acesso a equipamentos, como câmeras de vídeo, computadores e Internet.

A intenção do projeto $V 2$-East foi enfatizar a produção e discutir a situação do desenvolvimento artístico do Leste Europeu, facilitando co-produções com artistas e instituições do lado Ocidental. Apesar de estarem próximos geograficamente, muitos fazendo parte de regiões que até há poucos anos eram internas a um só país - como no caso de exrepúblicas soviéticas ou países desmembrados da Iugoslávia - o território de trocas de experiências e exposições foi a Internet, onde não encontravam entraves diplomáticos ou sectarismos étnicos que dificultassem a comunicação entre institutos de arte.

No trabalho organizado pela V2-East, o que nos chama a atenção é que, após a iniciativa de estruturar o contato entre grupos de pesquisadores e artistas de países do Leste Europeu, através da rede digital de informações, esses grupos estão desenvolvendo atividades integradas independentes. No início, comunicavam-se apenas pela rede que, pelo caráter global da Internet, era acessível (e efetivamente acessada) por grupos de outros continentes, e usavam como língua o inglês "crioulo", repleto de terminologias próprias à rede e misturado com palavras próprias a seus países. Gradativamente, grupos de regiões próximas começaram a se juntar e, em pouco tempo, com afinidades, criaram subgrupos onde adotaram a própria língua. Também com uma maior abertura política, começaram a organizar exposições e encontros reais - baseados no território geográfico - onde as trocas de experiências se efetivavam com mais força. Encontrando conexões por similaridade intelectual e artística, e não pela contigüidade geográfica, os grupos mostram seus trabalhos, discutem os problemas geopolíticos aos quais estão submetidos e, aos poucos, revertem essas relações para o território local.

Outra experiência importante vem sendo feita pelo jornal Le Monde Diplomatique, dando destaque às discussões sobre a influência da Internet nas transformações de países do Sul - sobretudo a África -, e à importância das possibilidades de liberdade de comunicação e troca de informações que esses meios trazem à vida social local. Mais uma vez, a idéia é a criação de um lugar de discussão livre, permanente, de troca de informações e planejamento de ações locais.

É claro que essas ações funcionam apenas quando as regiões envolvidas têm, ao menos, conexão telefônica, o que ainda é um luxo em grande parte dos países. Isso nos levaria a imaginar que o discurso da possibilidade de integração e troca de informações em escala global para incrementar as ações locais só atingiriam as regiões desenvolvidas que, inclusive, teriam outros meios de resolverem seus problemas. Vale então a pena analisarmos um último exemplo.

Em 23 de abril de 1997, o argelino Bassim Karkachi enviou uma mensagem a todos os participantes da lista de discussão do jornal Le Monde Diplomatique, pedindo informações sobre seu país. Desde 1992, quando o partido fundamentalista islâmico venceu as eleições, mas foi proibido de assumir o poder, uma onda de terror varre o país. Para aumentar o isolamento, as comunicações com a ex-colônia são ou controladas pelo governo ou bloqueadas pela milícia armada.

Milhares de argelinos vivem fora e conseguem poucas informações de seus familiares ou da situação interna cotidiana. Após a consulta de Karkachi, alguns membros do fórum do jornal enviaram mensagens sobre os 
poucos espaços da Argélia na Internet, sendo que alguns deles foram construídos por argelinos que vivem fora, com o intuito de possibilitar que sua população, espalhada pelo mundo, discuta os problemas nacionais o que, pelos meios tradicionais, como correio, rádio ou televisão, seria inviável.

\section{NOVAS FRONTEIRAS}

Uma das contradições da contemporaneidade é que temos a circulação de informações à velocidade da luz, ao mesmo tempo em que temos o bloqueio de circulação de pessoas, com fronteiras e centros de policiamento, criando uma população estacionada em algum subsolo da modernidade do outro.

Além de entendermos quais são as propriedades dos novos meios, devemos buscar compreender quais as transformações nas categorias éticas, sociais ou geopolíticas, por exemplo, que estão ocorrendo nestes anos recentes quando vivemos amalgamados numa teia informacional complexa. O ciberes-

Resumo: O ciberespaço é a trama informacional construída pelo entrelaçamento de meios de telecomunicação e informática. A Internet é uma de suas partes mais importantes e originou-se como estratégia de defesa norteamericana durante o período da Guerra Fria. Com o abrandamento do conflito bipolar, a rede alastrou-se em outros setores e adquiriu escala global. Sua força está em sua organização descentralizada, na manipulação de informações e ações feitas remotamente, e na inexistência de limites geopolíticos. Com sua potência global, o ciberespaço vem se mostrando campo de atuação de forças locais que, após a consolidação informacional no território digital, dinamizam transformações culturais no território geopolítico.

Palavras-chave: ciberespaço, território digital, Internet, censura, democracia paço, com sua trama global híbrida, independente de qualquer ligação geográfica, tendo base tecnológica em diversos meios, como rádio, televisão, telefone e computadores possibilita que pessoas e grupos se organizem por afinidades, discutam seus problemas, peçam e acessem informações e, longe da vigilância política, tentem construir realidades locais.

No entanto, continuaremos tendo um abismo entre as poucas regiões do mundo que vivem no ciberespaço e a grande maioria populacional que não tem acesso a essa forma de cultura. Isso continuará a existir.

Todavia, o que devemos pensar é como integrar culturalmente as pessoas que vivem em territórios entrelaçados no ciberespaço mas, por fatores alheios ao meio, encontram-se completamente afastadas ou apenas sofrendo seus efeitos colaterais, sem ter oportunidades de se envolverem na sua construção.

Abstract: Cyberspace is an informational scheme built by the mingling of the telecommunications media and computer science. The Internet is one of its most important parts and it originated as an American defense strategy during the Cold War. With the end of the bipolar conflict, the network spread into other sectors and took on a global scale. Its force lies is in its decentralized organization, in the manipulation of information and actions carried out remotely, and in the absence of geopolitical limits. With its global power, cyberspace has been revealing itself as a field for the performance of local forces that, after informational consolidation in the digital territory takes place, it stimulates cultural transformations in the geopolitical territory.

Key words: cyberspace, digital territory, Internet, censure, democracy 